\title{
The application of procalcitonin in respiratory diseases: an evaluation of the current research literature
}

\author{
Yun Tan ${ }^{1 \#}$, Xiujun Zhan ${ }^{2 \#}$, Haibin $\mathrm{Cui}^{3}$, Xiaoqian Chen ${ }^{4}$, Zengqian Hui ${ }^{5}$, Lanxiang Ma ${ }^{3}$ \\ ${ }^{1}$ Laboratory and Pathology, Shaanxi Corps Hospital of Chinese People's Armed Police Forces, Xi'an, China; ${ }^{2}$ Department of Laboratory, Jiamusi \\ Hospital of Traditional Chinese Medicine, Jiamusi, China; ${ }^{3}$ Second Department of Characteristic Medicine, Shaanxi Corps Hospital of Chinese \\ People's Armed Police Forces, Xi'an, China; ${ }^{4}$ Department of Anesthesiology, Shaanxi Corps Hospital of Chinese People's Armed Police Forces, \\ Xi'an, China; ${ }^{5}$ Department of Critical Care, Shaanxi Corps Hospital of Chinese People's Armed Police Forces, Xi'an, China \\ Contributions: (I) Conception and design: Y Tan, L Ma; (II) Administrative support: X Zhan, L Ma; (III) Provision of study materials or patients: \\ H Cui; (IV) Collection and assembly of data: Y Tan, X Zhan, H Cui, X Chen; (V) Data analysis and interpretation: Y Tan, Z Hui, L Ma; (VI) \\ Manuscript writing: All authors; (VII) Final approval of manuscript: All authors. \\ \#These authors contributed equally to this work. \\ Correspondence to: Lanxiang Ma. Second Department of Characteristic Medicine, Shaanxi Corps Hospital of Chinese People's Armed Police Forces, \\ Xi'an 710054, China. Email: 3059033685@qq.com.
}

Background Procalcitonin (PCT) can effectively identify bacterial infections and can be used for risk prediction and antimicrobial treatment in patients with unexplained fever and critically ill patients. In this study, statistical analyses of the literature were performed to clarify the application and research status of PCT in respiratory diseases. Future research directions are discussed.

Methods: A literature search was conducted using the Science Citation Index Expanded (SCI-EXPANDED) database in the Web of Science Core Collection (WOSCC). Published literature between 1995 and February 6, 2021 were searched using the following strategies: subject term = procalcitonin; and Web of Science categories = Respiratory System. Using the Citespace software, the literature on the application of PCT in patients with respiratory diseases was analyzed in terms of annual publication status, subject distribution, country/institution distribution, journal distribution, author distribution, and keywords.

Results: A total of 542 related research literatures were identified, with the number of published papers and the number of literature citations increasing yearly. Research was mainly concentrated in the United States, China, Switzerland, and other countries, with countries such as the United Kingdom, the United States, and Canada being involved in international collaborations. Research institutions were mainly universities or hospitals such as the University Hospital of Basel, University of Barcelona, and Northwestern University. In particular, the University Hospital of Basel had extensive inter-hospital collaborations. Stolz et al. published many related papers, but the centrality value was low. Authors including Christ-Crain M, Schuetz P, and Stolz D were highly cited. Journals such as the American Journal of Respiratory and Critical Care Medicine, Chest, and the European Respiratory Zournal were more influential. Keyword analysis showed that sepsis and pneumonia are the current hot topics.

Conclusions: Related papers mainly focused on respiratory infections, especially sepsis and pneumonia. There were also a small number of studies suggesting that PCT is related to tumors.

Keywords: Procalcitonin (PCT); respiratory system disease; bibliometric analysis

Submitted Feb 25, 2021. Accepted for publication Apr 28, 2021.

doi: 10.21037/apm-21-840

View this article at: http://dx.doi.org/10.21037/apm-21-840 


\section{Introduction}

Procalcitonin (PCT) is a highly specific biomarker of infectious inflammatory responses (1). As a sensitive indicator of bacterial infection in the body, its expression increases significantly in the early stages of infections. Often, when PCT levels are elevated, parasitic infections, chronic inflammation, and autoimmune diseases are not yet obvious at clinical examinations. PCT has important clinical significance in identifying the presence of bacterial infections, especially in patients with unexplained fever and critically ill patients, risk prediction, and antimicrobial treatment guidance (2-5). Respiratory tract infections are the most common disease in clinical practice. It is often crucial to identify these bacterial infections as lung infections can easily develop into sepsis. In addition, severely ill patients often have lung infections and PCT is required as a reference for clinical diagnosis and disease monitoring (6-9). Furthermore, some studies have shown that circulating PCT levels are related to lung tumors, chronic obstructive pulmonary diseases (COPDs), asthma, and pulmonary embolisms (10-13). In 2020, PCT was widely used in coronavirus disease 2019 (COVID-19) infection management world-wide (14). This study sought to clarify the application and research status of PCT in respiratory diseases through statistical analysis of the literature and to suggest future research directions.

\section{Methods}

\section{Database}

A literature search was conducted using the Science Citation Index Expanded (SCI-EXPANDED) database in the Web of Science Core Collection (WOSCC) to analyze the application of PCT in respiratory system diseases.

\section{Search strategy}

Literature published between 1995 and February 6, 2021 were included in the search. The following search formulas were applied: (I) subject term = procalcitonin; (II) search scope, Web of science categories = Respiratory System; and (III) the intersection of the results from formulas 1 and 2 .

\section{Analysis of data}

The full record of the search results and the cited references were exported in text format. The Citespace software
Table 1 Analysis of the search result document types

\begin{tabular}{lcc}
\hline Literature type & Record & $\%$ of 542 \\
\hline Article & 272 & 50.18 \\
Meeting abstract & 160 & 29.52 \\
Review & 47 & 8.67 \\
Editorial material & 31 & 5.72 \\
Letter & 31 & 5.72 \\
Proceedings paper & 11 & 2.03 \\
Early access & 4 & 0.74 \\
Book chapter & 3 & 0.55 \\
Correction & 1 & 0.18 \\
\hline
\end{tabular}

was used to analyze the annual publication status, subject distribution, country/institution distribution, journal distribution, author distribution, and keywords of PCT in respiratory diseases.

\section{Results}

\section{Literature search results}

There were a total of 542 related research documents (18 of which were marked with 2 types of documents, and thus, a total of 560 records were collected at the time of statistical analysis). Of these, 272 were original articles, 160 were conference abstracts, 47 were reviews, and 31 were editorial materials including 13 letters, 11 conference papers, 4 priority publications, 3 books, and 1 correction (Table 1). The number of related papers published annually showed an upward trend (Table 2, Figure 1). The citation frequency was 12,147 in total, the h-index count was 54 , and the average number of citations per item was 22.41. The number of citations in the literature also increased yearly (Figure 2).

\section{Distribution of countries and institutions}

The CiteSpace V software was used to generate national visualization maps (Figure 3) where $\mathrm{N}=75$ and $\mathrm{E}=190$ $(\mathrm{N}$ represents the number of network nodes and $\mathrm{E}$ represents the number of connections) and institutional visualization maps (Figure 4) where $\mathrm{N}=1,000$ and $\mathrm{E}=2,418$. The top 5 countries with publication volume were the United States, China, Switzerland, Spain, and Germany. The top 5 centrally ranked countries were the United Kingdom, the United States, Canada, Switzerland, and 
Table 2 Science Citation Index (SCI) annual distribution

\begin{tabular}{|c|c|c|}
\hline Year of publication & Record & $\%$ of 542 \\
\hline 2020 & 43 & 7.93 \\
\hline 2019 & 36 & 6.64 \\
\hline 2018 & 43 & 7.93 \\
\hline 2017 & 44 & 8.12 \\
\hline 2016 & 53 & 9.78 \\
\hline 2015 & 40 & 7.38 \\
\hline 2014 & 34 & 6.27 \\
\hline 2013 & 35 & 6.46 \\
\hline 2012 & 32 & 5.90 \\
\hline 2011 & 51 & 9.41 \\
\hline 2010 & 26 & 4.80 \\
\hline 2009 & 33 & 6.09 \\
\hline 2008 & 15 & 2.77 \\
\hline 2007 & 15 & 2.77 \\
\hline 2006 & 10 & 1.85 \\
\hline 2005 & 10 & 1.85 \\
\hline 2004 & 3 & 0.55 \\
\hline 2003 & 4 & 0.74 \\
\hline 2002 & 3 & 0.55 \\
\hline 2001 & 5 & 0.92 \\
\hline 2000 & 2 & 0.37 \\
\hline 1999 & 2 & 0.37 \\
\hline 1998 & 2 & 0.37 \\
\hline 1995 & 1 & 0.18 \\
\hline
\end{tabular}

Denmark (Tables 3,4). Institutions with a large number of publications included universities or hospitals such as the University Hospital of Basel, University of Barcelona, and Northwestern University (Tables 5,6). Authors with a large number of publications included Stolz, Mueller, and Schuetz (Table 7, Figure 5). Although author centrality was ranked, the centrality values of the top 10 authors were all lower than 0.001 , suggesting that author cooperation was very scattered and not centralized. The analysis showed that Christ-Crain M, Schuetz P, Stolz D, and other authors were cited very frequently, but the centrality value was not high and the top 10 centrality ranking authors were cited relatively less than Christ-Crain M, Schuetz P, and Stolz D (Tables 8,9, Figure 6).

\section{Distribution of journals}

There were a total of 542 PCT respiratory-related documents, involving 54 journals, of which 14 journals had more than 10 related articles. These top 14 journals together published a total of 409 respiratory-related articles, accounting for $75.46 \%$ of the total literature (Table 10). The top 10 journals are listed in Table 11 by frequency and Table 12 by centrality of citations. Based on the above results, it can be speculated that journals such as the American fournal of Respiratory and Critical Care Medicine, Chest, and the European Respiratory fournal have greater influence in this field.

\section{Keywords that reflect the research hotspots and frontiers in this field}

Using the CiteSpace V software, a keyword co-occurrence

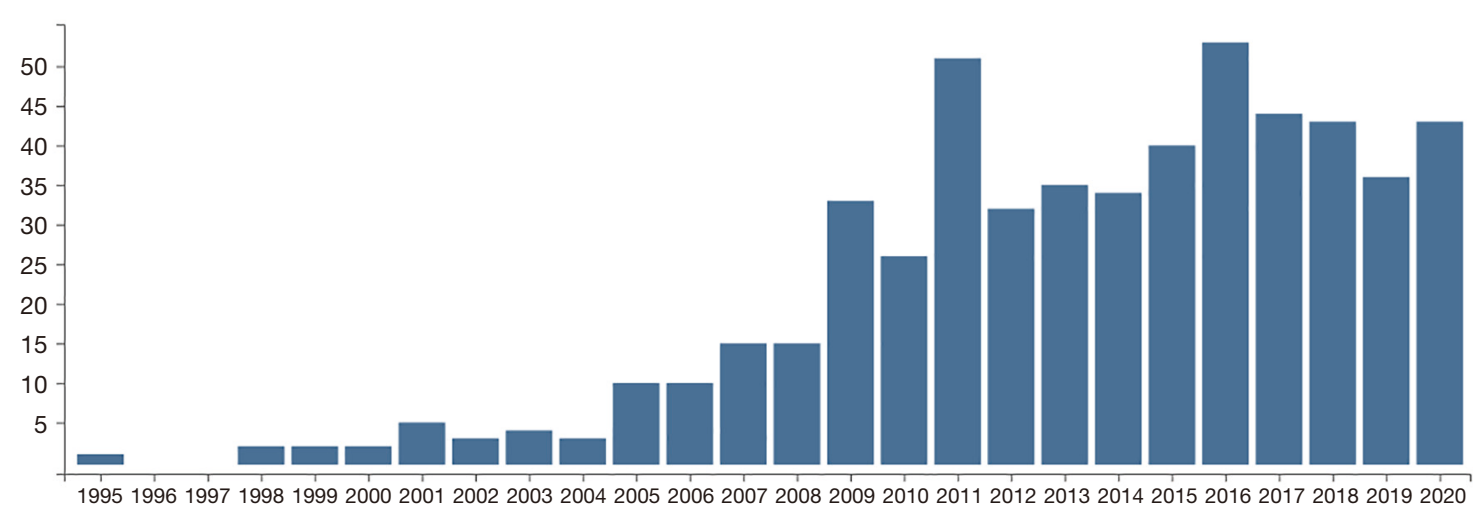

Figure 1 Annual publications. $\mathrm{X}$ axis represents the year of publications and $\mathrm{Y}$ axis represents the number of publications. 


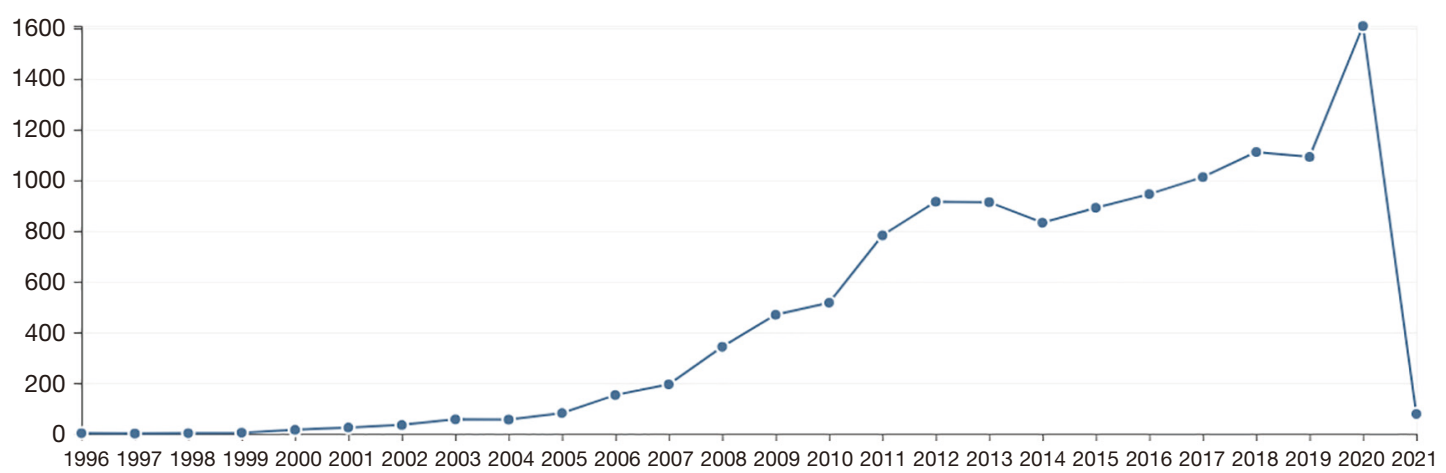

Figure 2 Annual citations. $\mathrm{X}$ axis represents the year of citations and $\mathrm{Y}$ axis represents the number of citations.

Figure 3 Country visualization map.

map was generated (Figure 7, N=574, E=3,327). The top 10 keywords with frequency and centrality are listed in Tables 13 and 14 . It can be seen that sepsis, pneumonia, and infection are the current research hotspots. CiteSpace was used for burst detection of keywords with higher frequency (Figure 8). The results showed that the research hotspots reflected by the keywords gradually changed over time, from the early diagnosis of infection or pneumonia to evidence-based medicine.

\section{Discussion}

This study analyzed the relevant literature on the application of PCT in respiratory diseases. The number of relevant publications increases every year, and the research was mainly concentrated in the United States, the United Kingdom, Europe. In addition, a significant number of studies in this field have been conducted in China. However, there have been few international cooperation studies. Moreover, the research has been mainly limited to several research teams in several university research institutions or hospitals. Although these research teams have a large number of publications, they have relatively few international collaborations. The related literature was mainly published in several professional journals. These results suggested that the application of PCT in respiratory diseases has received extensive attention, but research in related fields is still relatively limited worldwide. Biomarkers are an important advancement in modern medicine. There is much evidence supporting classical markers after decades 


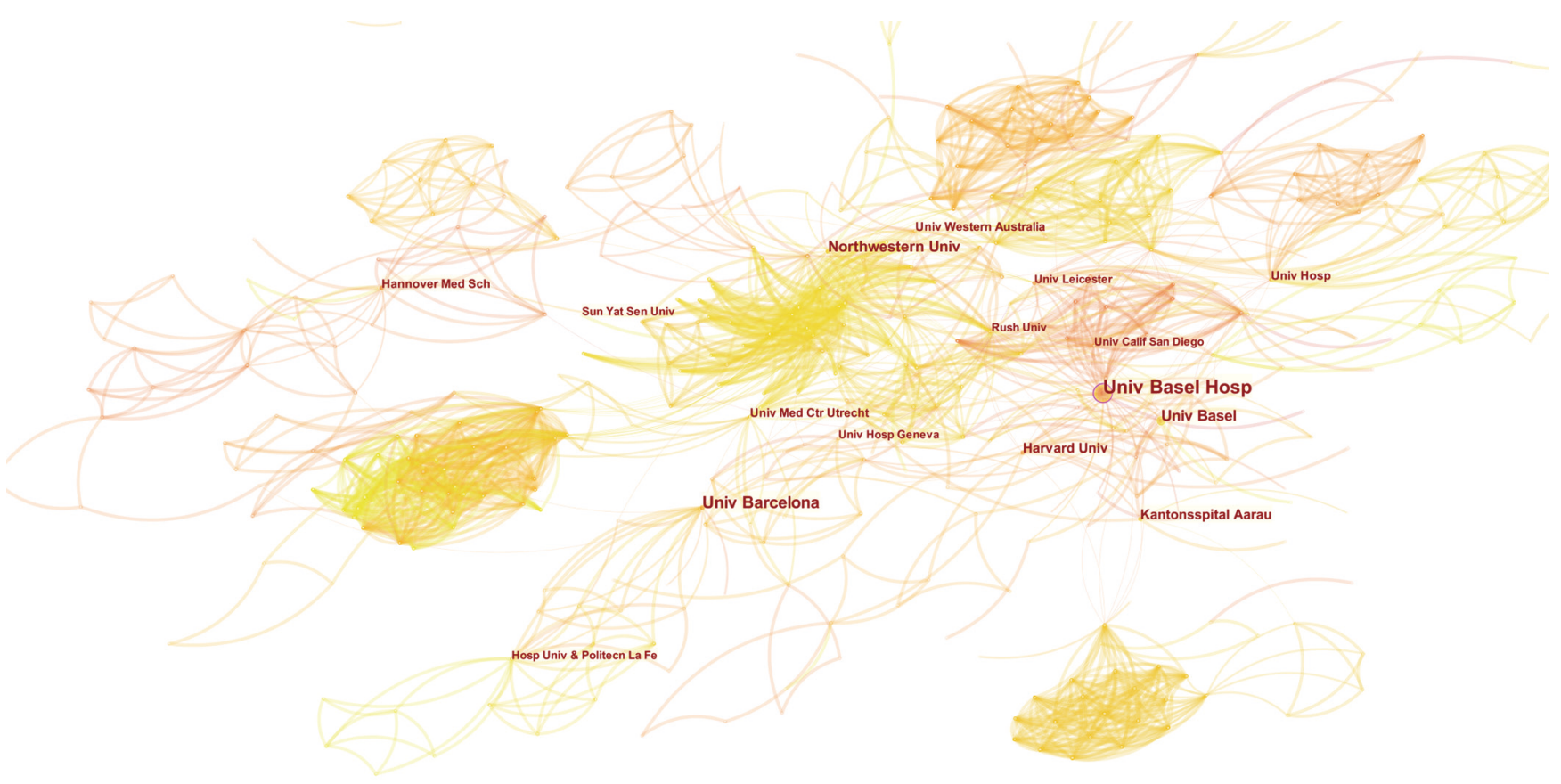

Figure 4 An institution visualization map.

Table 3 The top 10 countries based on publication

\begin{tabular}{lcc}
\hline No. & Country & Frequency \\
\hline 1 & USA & 122 \\
2 & China & 56 \\
3 & Switzerland & 55 \\
4 & Spain & 49 \\
5 & Germany & 47 \\
6 & England & 37 \\
7 & France & 34 \\
8 & Italy & 21 \\
9 & Netherlands & 18 \\
10 & Australia & 17 \\
\hline
\end{tabular}

USA, United State of America.

of continuous research $(15,16)$. For example, C-reactive protein (CRP) has landmark significance in detecting inflammation $(17,18)$, and troponin has an irreplaceable role in diagnosing myocardial infarction $(19,20)$. Therefore, researchers should carry out more clinical studies, especially multi-center studies, to observe the relationship between
Table 4 The top 10 countries based on centrality

\begin{tabular}{lcc}
\hline No. & Country & Centrality \\
\hline 1 & England & 0.26 \\
2 & USA & 0.10 \\
3 & Canada & 0.08 \\
4 & Switzerland & 0.07 \\
5 & Denmark & 0.06 \\
6 & Germany & 0.06 \\
7 & Spain & 0.06 \\
8 & Belgium & 0.04 \\
9 & Australia & 0.04 \\
10 & Poland & 0.03 \\
\hline
\end{tabular}

PCT and respiratory diseases, in particular, respiratory infectious diseases.

Through the analysis of keywords, the current research hotspots in the field of respiratory diseases appear to be sepsis, pneumonia, and infections. However, according to indepth analysis of the literature, increasingly, more and more 
Table 5 The top 10 institutions based on publication

\begin{tabular}{llc}
\hline No. & Institution & Frequency \\
\hline 1 & University of Basel Hospital & 27 \\
2 & University of Barcelona & 18 \\
3 & University of Basel & 13 \\
4 & Northwestern University & 13 \\
5 & Kantonsspital Aarau & 10 \\
6 & Harvard University & 9 \\
7 & University of Western Australia & 7 \\
8 & University Medicine Centre Utrecht & 7 \\
9 & Hannover Medical School & 7 \\
10 & University of California San Diego & 6 \\
\hline
\end{tabular}

Table 6 The top 10 institutions based on centrality

\begin{tabular}{llc}
\hline No. & Institution & Centrality \\
\hline 1 & University of Basel Hospital & 0.12 \\
2 & UMass Memorial Medical Centre & 0.08 \\
3 & University of Barcelona & 0.07 \\
4 & Harvard University & 0.05 \\
5 & University of California San Diego & 0.05 \\
6 & Northwestern Univ & 0.04 \\
7 & Massachusetts General Hospital & 0.04 \\
8 & Kantonsspital Liestal & 0.04 \\
9 & Johns Hopkins University & 0.04 \\
10 & Brahms AG & 0.04 \\
\hline
\end{tabular}

studies are examining the relationship between PCT and other diseases of the respiratory system, such as the value of PCT in the diagnosis and prognosis of lung cancer patients (10,11,21-24). Studies have shown that even if patients with lung cancer are not co-infected, the average serum PCT levels were higher than that of non-infected patients without lung cancer, and the higher the PCT levels, the worse the prognosis $(10,22,23)$. Other reports have also demonstrated that serum PCT levels can help distinguish between pulmonary embolism and community-acquired pneumonia (25). In contrast, Ateş et al. reported that compared with PCT and other indicators, the ratio of neutrophils to lymphocytes to D-dimers is more helpful
Table 7 The top 10 authors based on publications

\begin{tabular}{llc}
\hline No. & Authors & Number \\
\hline 1 & Stolz D & 19 \\
2 & Mueller B & 19 \\
3 & Schuetz P & 17 \\
4 & Tamm M & 15 \\
5 & Torres A & 14 \\
6 & Christcrain M & 13 \\
7 & Menendez R & 12 \\
8 & Bingisser R & 7 \\
9 & Welte R & 6 \\
10 & Pertseva T & 6 \\
\hline
\end{tabular}

in distinguishing pulmonary embolism from communityacquired pneumonia (12). Other studies have shown that in children with severe asthma, serum PCT levels were less than $0.5 \mathrm{ng} / \mathrm{mL}$ in $75 \%$ of children. Further analysis showed that there was no close relationship between the lung infiltration on chest radiograph and the increase in PCT (13). In patients with COPD, elevated PCT levels can help distinguish between acute onset and stable COPD $(26,27)$. However, a literature review suggested that the current available evidence is still relatively weak, and further research is needed. The cut-off value of PCT is yet to be determined to assist in the clinical determination of acute COPD (28). Although these studies have not yet become the mainstream of research, there is an increasing awareness that PCT is not only related to respiratory infections, but may also be related to lung tumors and other airway diseases. Further in-depth research and increased collaboration between institutions and countries/regions will be necessary to develop strong evidence-based medical data.

This study had certain limitations. Due to the methodological limitations of the study, only a basic analysis of the relevant literature could be performed, and thus, individual studies may have been omitted due to different classification methods. Concurrently, due to the large number of included articles, it was not possible to carry out detailed analyses and statistics on each document. Therefore, the present study may only reflect a macroscopic view of the relevant research field. Finally, this research is limited to literature analysis, and it may be more meaningful to add some clinical research results. 


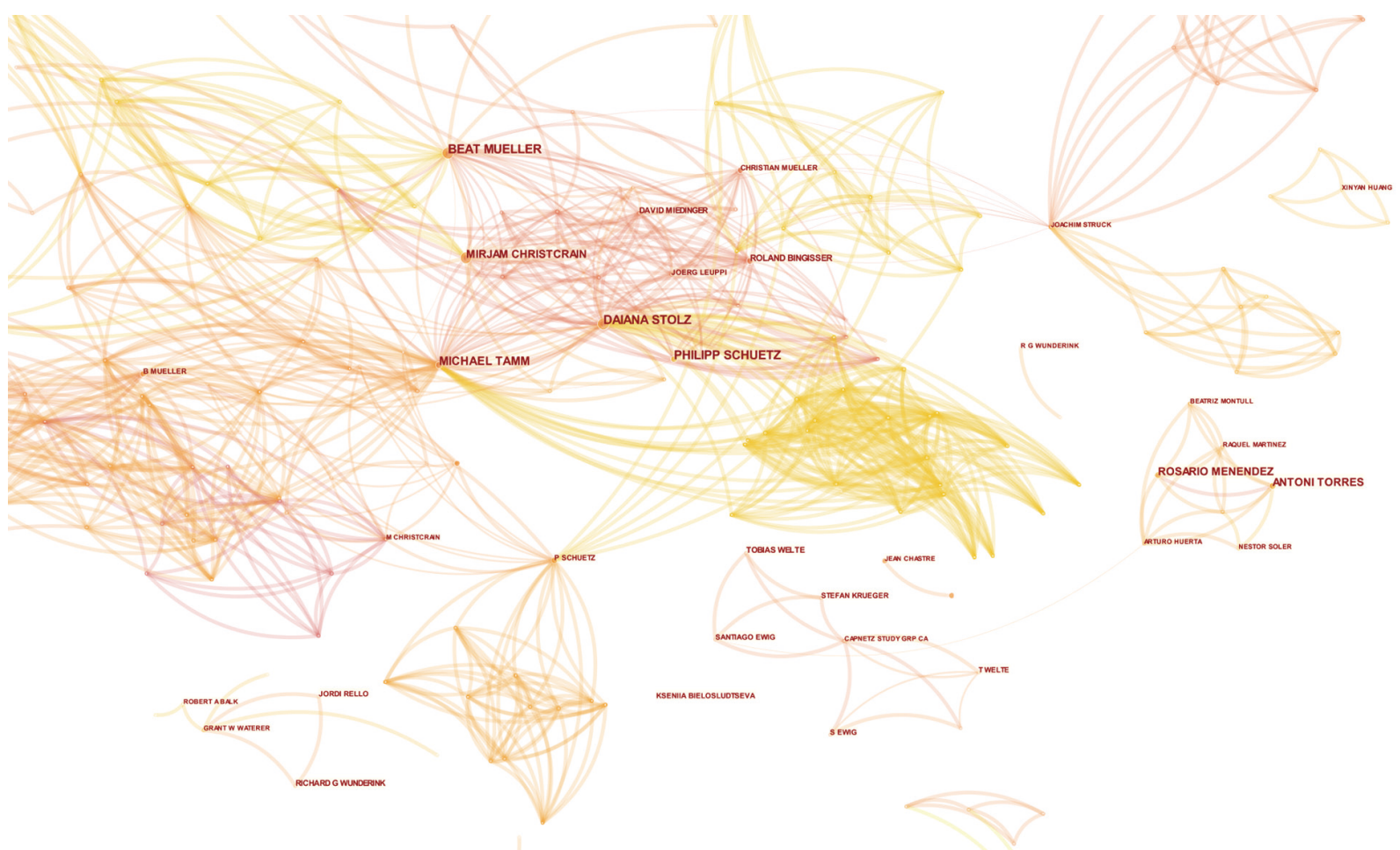

Figure 5 A visualization map of authors.

Table 8 Top 10 co-cited authors based on frequency

\begin{tabular}{llc}
\hline No. & Authors & Frequency \\
\hline 1 & Christ-Crain M & 142 \\
2 & Schuetz P & 119 \\
3 & Stolz D & 90 \\
4 & Kruger S & 60 \\
5 & Muller B & 57 \\
6 & Fine MJ & 56 \\
7 & Mandell LA & 49 \\
8 & Menendez R & 47 \\
9 & Niederman MS & 46 \\
10 & Luyt CE & 43 \\
\hline
\end{tabular}

Table 9 Top 10 co-cited authors based on centrality

\begin{tabular}{lll}
\hline No. & Authors & Centrality \\
\hline 1 & Assicot M & 0.23 \\
2 & Bone RC & 0.17 \\
3 & Anthonisen NR & 0.15 \\
4 & Aouifi A & 0.13 \\
6 & Bernard GR & 0.13 \\
7 & Reith HB & 0.11 \\
8 & Akgun S & 0.11 \\
9 & Becker KL & 0.1 \\
10 & Brunkhorst FM & 0.1 \\
11 & Gibot S & 0.09 \\
\hline
\end{tabular}




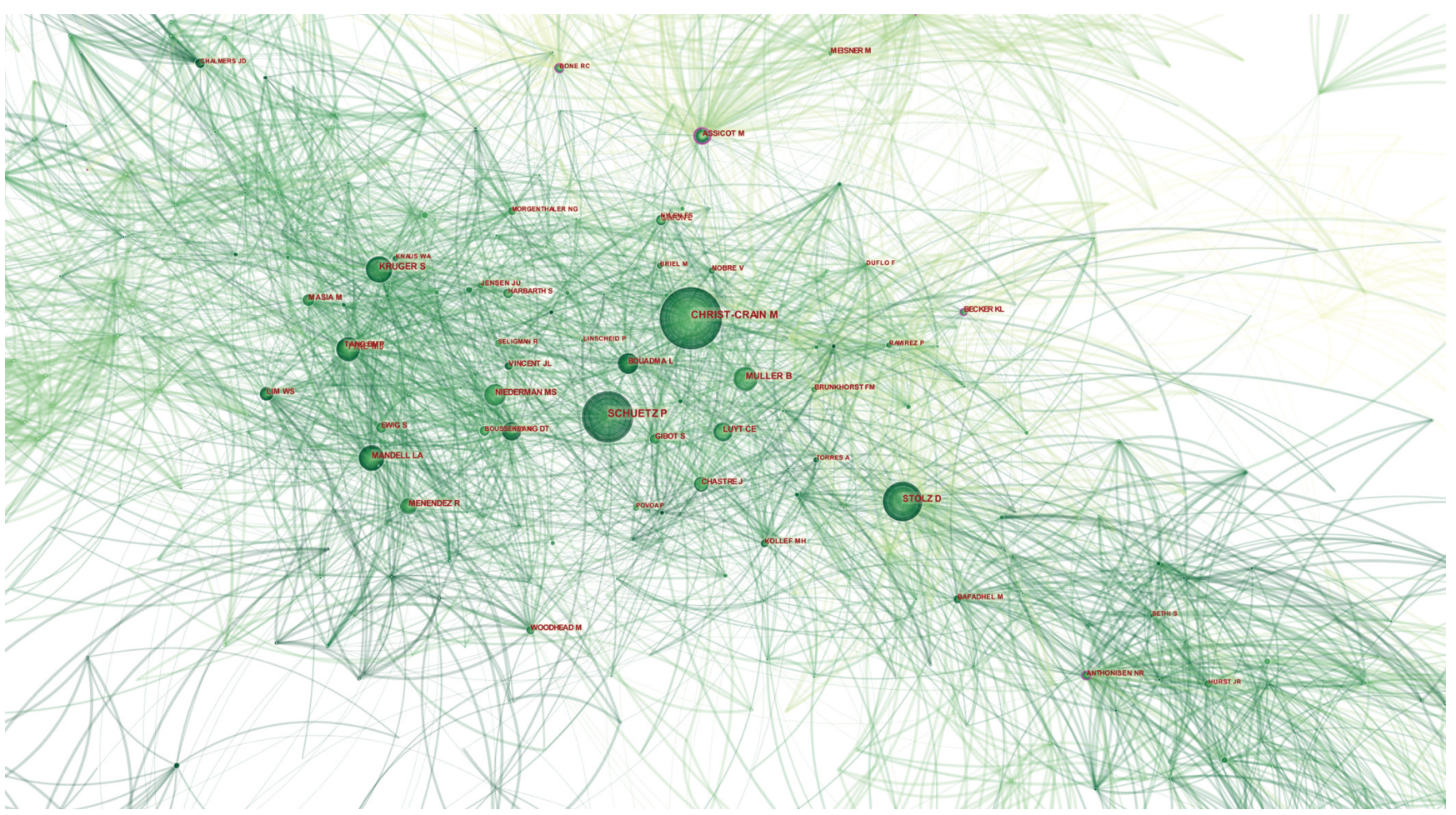

Figure 6 A visualization map of co-cited authors.

Table 10 The top 14 journals in terms of publications

\begin{tabular}{llcc}
\hline No. & Journals & Record & \% of 542 \\
\hline 1 & American Journal of Respiratory and Critical Care Medicine & 95 & 17.53 \\
2 & Chest & 82 & 15.13 \\
3 & European Respiratory Journal & 71 & 13.10 \\
4 & Respirology & 40 & 7.38 \\
5 & Thorax & 21 & 3.88 \\
6 & Current Opinion in Pulmonary Medicine & 17 & 3.14 \\
7 & Annals of Thoracic Surgery & 11 & 2.03 \\
8 & Pediatric Pulmonology & 11 & 2.03 \\
9 & Respiratory Research & 11 & 2.03 \\
10 & BMC Pulmonary Medicine & 1.85 \\
11 & International Journal of Chronic Obstructive Pulmonary Disease & 1.85 \\
12 & Respiratory Care & 10 & 1.85 \\
13 & Respiratory Medicine & 10 & 1.85 \\
14 & Revue Des Maladies Respiratoires & 10 & 1.85 \\
\hline
\end{tabular}


Table 11 The top 10 journals in terms of citation

\begin{tabular}{llc}
\hline No. & Journals & Frequency \\
\hline 1 & Chest & 267 \\
2 & Am J Resp Crit Care & 253 \\
3 & Eur Respir J & 216 \\
4 & Lancet & 211 \\
5 & New Engl J Med & 204 \\
6 & Crit Care Med & 197 \\
7 & Clin Infect Dis & 182 \\
8 & Thorax & 170 \\
9 & Intens Care Med & 169 \\
10 & Crit Care & 161 \\
\hline
\end{tabular}

Table 12 The top 10 journals in terms of centrality

\begin{tabular}{lll}
\hline No. & Journals & Centrality \\
\hline 1 & Am Rev Respir Dis & 0.14 \\
2 & Acta Paediatr & 0.12 \\
3 & Am J Emerg Med & 0.10 \\
4 & Eur J Clin Microbiol & 0.10 \\
5 & BMJ-Brit Med J & 0.09 \\
6 & Ann Intern Med & 0.07 \\
7 & Am Surgeon & 0.06 \\
8 & Blood & 0.06 \\
9 & Clin Chem Lab Med & 0.06 \\
10 & Am J Med & 0.06 \\
\hline
\end{tabular}

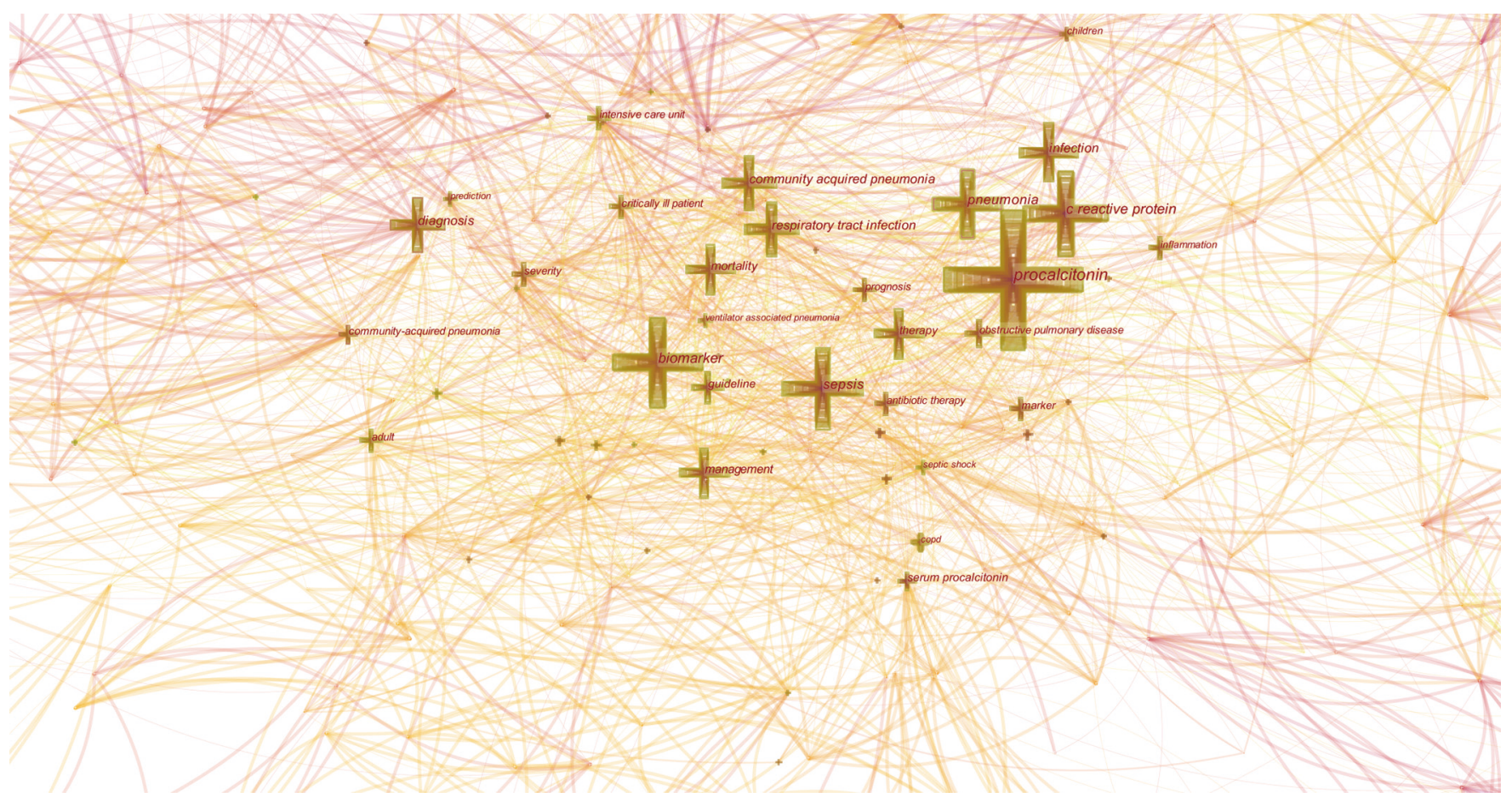

Figure 7 Keyword visualization map generated by the CiteSpace V software. 
Table 13 The top 10 keywords in terms of frequency

\begin{tabular}{llc}
\hline No. & Keywords & Frequency \\
\hline 1 & Procalcitonin & 227 \\
2 & CRP & 112 \\
3 & Biomarker & 108 \\
4 & Sepsis & 87 \\
5 & Pneumonia & 82 \\
6 & Infection & 68 \\
7 & CAP & 64 \\
8 & Diagnosis & 63 \\
9 & Respiratory tract infection & 62 \\
10 & Mortality & 55 \\
\hline
\end{tabular}

CAP, community-acquired pneumonia; CRP, C reaction protein.
Table 14 The top 10 keywords in terms of centrality

\begin{tabular}{llc}
\hline No. & Keywords & Centrality \\
\hline 1 & Diagnosis & 0.14 \\
2 & Children & 0.14 \\
3 & Pneumonia & 0.11 \\
4 & CAP & 0.11 \\
5 & CRP & 0.10 \\
6 & Expression & 0.10 \\
7 & Mechanical ventilation & 0.10 \\
8 & Serum procalcitonin & 0.09 \\
9 & Intensive care unit & 0.08 \\
10 & Inflammation & 0.08 \\
\hline
\end{tabular}

CAP, community-acquired pneumonia; CRP, C reaction protein.

\begin{tabular}{llrl} 
& \multicolumn{2}{c}{ Top 13 keywords with the Strongest Citation Bursts } \\
\multicolumn{1}{c}{ Keywords } & Year Strength Begin End \\
cardiopulmonary bypass & 1995 & 3.4 & 19982004 \\
ventilator-associated pneumonia & 1995 & 3.85 & 20052011 \\
marker & 1995 & 5.120082012 \\
severity & 1995 & 4.52 & 20082010 \\
c reactive protein & 1995 & 4.2320082012 \\
antibiotic therapy & 1995 & 4.0120082012 \\
procalcitonin guidance & 1995 & 3.620092010 \\
antibiotic use & 1995 & 4.420112012 \\
respiratory tract infection & 1995 & 4.33 & 20112012 \\
metaanalysis & 1995 & 4.37 & 20142018 \\
adult & 1995 & 3.74 & 20162020 \\
COPD & 1995 & 5.320172018 \\
obstructive pulmonary disease & 1995 & 3.5320172018 \\
\hline
\end{tabular}

Figure 8 The burst test of keywords using CiteSpace.

\section{Acknowledgments}

Funding: None.

\section{Footnote}

Conflicts of Interest: All authors have completed the ICMJE uniform disclosure form (available at http://dx.doi. org/10.21037/apm-21-840). The authors have no conflicts of interest to declare.

Ethical Statement: The authors are accountable for all aspects of the work in ensuring that questions related to the accuracy or integrity of any part of the work are appropriately investigated and resolved.

Open Access Statement: This is an Open Access article distributed in accordance with the Creative Commons Attribution-NonCommercial-NoDerivs 4.0 International License (CC BY-NC-ND 4.0), which permits the noncommercial replication and distribution of the article with the strict proviso that no changes or edits are made and the original work is properly cited (including links to both the formal publication through the relevant DOI and the license). 
See: https://creativecommons.org/licenses/by-nc-nd/4.0/.

\section{References}

1. Hamade B, Huang DT. Procalcitonin: Where Are We Now? Crit Care Clin 2020;36:23-40.

2. Schuetz P, Wirz Y, Sager R, et al. Procalcitonin to initiate or discontinue antibiotics in acute respiratory tract infections. Cochrane Database Syst Rev 2017;10:CD007498.

3. Creamer AW, Kent AE, Albur M. Procalcitonin in respiratory disease: use as a biomarker for diagnosis and guiding antibiotic therapy. Breathe (Sheff) 2019;15:296-304.

4. Huang DT, Yealy DM, Filbin MR, et al; ProACT Investigators. Procalcitonin-Guided Use of Antibiotics for Lower Respiratory Tract Infection. N Engl J Med 2018;379:236-49.

5. Choi JJ, McCarthy MW. Novel applications for serum procalcitonin testing in clinical practice. Expert Rev Mol Diagn 2018;18:27-34.

6. Schuetz P, Bolliger R, Merker M, et al. Procalcitoninguided antibiotic therapy algorithms for different types of acute respiratory infections based on previous trials. Expert Rev Anti Infect Ther 2018;16:555-64.

7. Kamat IS, Ramachandran V, Eswaran H, et al. Procalcitonin to Distinguish Viral From Bacterial Pneumonia: A Systematic Review and Meta-analysis. Clin Infect Dis 2020;70:538-42.

8. Wussler D, Kozhuharov N, Tavares Oliveira M, et al. Clinical Utility of Procalcitonin in the Diagnosis of Pneumonia. Clin Chem 2019;65:1532-42.

9. Schuetz P, Wirz Y, Sager R, et al. Effect of procalcitoninguided antibiotic treatment on mortality in acute respiratory infections: a patient level meta-analysis. Lancet Infect Dis 2018;18:95-107.

10. Murat Sedef A, Kose F, Taner Sumbul A, et al. Prognostic value of procalcitonin in infection-related mortality of cancer patients. J BUON 2016;21:740-4.

11. Mohamed S, Abdelhaffez A, Abd El-Aziz N. Serum Procalcitonin in Patients With Combined Lung Cancer and Idiopathic Pulmonary Fibrosis (LC-IPF). Cureus 2020;12:e9507.

12. Ateş H, Ateş İ, Bozkurt B, et al. What is the most reliable marker in the differential diagnosis of pulmonary embolism and community-acquired pneumonia? Blood Coagul Fibrinolysis 2016;27:252-8.

13. Samraj RS, Crotty EJ, Wheeler DS. Procalcitonin Levels in Critically Ill Children With Status Asthmaticus. Pediatr
Emerg Care 2019;35:671-4.

14. Hu R, Han C, Pei S, et al. Procalcitonin levels in COVID-19 patients. Int J Antimicrob Agents 2020;56:106051.

15. Aronson JK, Ferner RE. Biomarkers-A General Review. Curr Protoc Pharmacol 2017;76:9.23.1-9.23.17.

16. Pierrakos C, Vincent JL. Sepsis biomarkers: a review. Crit Care 2010;14:R15.

17. Pathak A, Agrawal A. Evolution of C-Reactive Protein. Front Immunol 2019,10:943.

18. Ridker PM, MacFadyen JG, Everett BM, et al. Relationship of C-reactive protein reduction to cardiovascular event reduction following treatment with canakinumab: a secondary analysis from the CANTOS randomised controlled trial. Lancet 2018;391:319-28.

19. Shah ASV, Anand A, Strachan FE, et al. High-sensitivity troponin in the evaluation of patients with suspected acute coronary syndrome: a stepped-wedge, cluster-randomised controlled trial. Lancet 2018;392:919-28.

20. Chapman AR, Lee KK, McAllister DA, et al. Association of High-Sensitivity Cardiac Troponin I Concentration With Cardiac Outcomes in Patients With Suspected Acute Coronary Syndrome. JAMA 2017;318:1913-24. Erratum in: JAMA 2018;319:1168.

21. Avrillon V, Locatelli-Sanchez M, Folliet L, et al. Lung cancer may increase serum procalcitonin level. Infect Disord Drug Targets 2015;15:57-63.

22. Kajikawa S, Ohashi W, Kato Y, et al. Prognostic impact of serum procalcitonin in non-small cell lung cancer. Tumori 2020. [Epub ahead of print]. doi: 10.1177/0300891620966647.

23. Pardo-Cabello AJ, Manzano-Gamero V. Small cell lung cancer elevates procalcitonin levels in the absence of infection. Lung Cancer 2019,134:272-3.

24. Soeroso NN, Tanjung MF, Afiani D, et al. Procalcitonin Level in Non-Small Cell Lung Cancer Patients among Indonesian Population. Open Access Maced J Med Sci 2018;6:2123-7.

25. Köktürk N, Kanbay A, Bukan N, et al. The value of serum procalcitonin in differential diagnosis of pulmonary embolism and community-acquired pneumonia. Clin Appl Thromb Hemost 2011;17:519-25.

26. Borsi H, Nia EP, Mal-Amir MD, et al. Relationship between serum procalcitonin level and chronic obstructive pulmonary disease. J Family Med Prim Care 2019;8:738-40.

27. Pandey S, Garg R, Kant S, et al. Serum procalcitonin levels in chronic obstructive pulmonary disease patients in 
North Indian Population. Ann Afr Med 2019;18:103-7.

28. Pantzaris ND, Spilioti DX, Psaromyalou A, et al. The Use of Serum Procalcitonin as a Diagnostic and Prognostic Biomarker in Chronic Obstructive Pulmonary Disease
Exacerbations: A Literature Review Update. J Clin Med Res 2018;10:545-51.

(English Language Editor: J. Teoh)

Cite this article as: Tan Y, Zhan X, Cui H, Chen X, Hui Z, $\mathrm{Ma} \mathrm{L}$. The application of procalcitonin in respiratory diseases: an evaluation of the current research literature. Ann Palliat Med 2021;10(5):5329-5340. doi: 10.21037/apm-21-840 